\title{
Analisis Daya Dukung Bored Pile Pada Pembangunan Pondasi Jembatan Kali Kenteng dan Kali Serang Segmen Susukan di Ruas Jalan Tol Salatiga-Kartasura, PT.Waskita Karya (Persero), Kabupaten Semarang, Provinsi Jawa Tengah
}

\author{
Reza Afrizona Fauzih ${ }^{1 *}$, Najib Najib ${ }^{1}$, Narulita Santi ${ }^{1}$ \\ ${ }^{1}$ Departemen Teknik Geologi Universitas Diponegoro \\ Jl. Profesor H. Soedarto SH., Tembalang, Semarang, Jawa Tengah 50275-Indonesia
}

\begin{abstract}
Abstrak
Jembatan Kali Kenteng dan Kali Serang merupakan salah satu proyek dari 4 pembangunan jembatan di ruas jalan tol Salatiga - Kartasura (STA 47+860.50 48+348.52). Jembatan ini terletak di terusan Kali Kenteng dan Kali Serang yang terdapat pada daerah Susukan, Kabupaten Semarang. Permasalahan yang ditemukan pada sepanjang jalur Salatiga ini adalah akibat morfologi dan kelerengan yang cukup curam, grid elevasinya mencapai $10-15^{\circ}$ yang dapat membahayakan pengguna jalan dan dapat membuat kemacetan panjang. Tujuan dari penelitian tersebut untuk mengetahui persebaran tanah dan batuan secara vertikal dan lateral, mengetahui kapasitas daya dukung yang diijinkan pada pondasi pembangunan jembatan, dan mengetahui litologi dan kedalaman yang tepat sebagai batuan pondasi jembatan untuk rekomendasi desain pondasi tiang pancang. Jenis pondasi yang digunakan dalam pembangunan jembatan tersebut yakni pondasi bored pile. Kapasitas daya dukung maksimum dan beban maksimum yang diizinkan ditentukan berdasarkan analisis data yakni uji SPT (Standart Penetration Test), param sifat fisik tanah (berat jenis) dan sifat mekanik tanah (kohesi dan sudut geser dalam). Berdasarkan pemetaan geologi teknik, daerah penelitian memiliki satuan breksi vulkanik dan satuan lempung. Hasil perhitungan menggunakan metode Uji SPT dan sifat fisik dan mekanik tanah, menunjukkan nilai diameter 1,5 mampu menjadi pondasi daerah tersebut pada kedalaman yang berbeda. Nilai yang direkomendasikan menggunakan pengujian SPT lebih cocok karena memiliki nilai daya dukung yang lebih besar dibandingkan dengan menggunakan metode sifat fisik dan mekanik tanah. Batuan yang cocok menjadi pondasi adalah breksi vulkanik.
\end{abstract}

Kata Kunci : Daya Dukung Tanah; jembatan, Segmen Susukan; Standard Penetration Test; Pondasi Bored Pile.

\begin{abstract}
Kenteng and Serang rivers bridge is one of the 4 bridge development project at Salatiga - Kartasura highway roads (STA 47+860.50 48+348.52). This bridge located in Kenteng and Serang rivers canal at Susukan area, Semarang District. The problems found along the Salatiga city lane are due to steep morphology and slope, the elevation grid reaches 10-15 degrees, can endanger road users and create long congestion. The purpose of the study was to determine the distribution of soil and rock vertically and laterally, to determine the allowable bearing capacity of the foundation of the bridge construction, and to know the lithology and depth that are suitable of the pole as a recommendation for the company. One of the foundation used in the development of the bridge is bored pile foundation. Ultimate bearing capacity and allowable bearing capacity is determined by the SPT (Standart Penetration Test) analysis result test, physical properties of the soil param (specific gravity) and mechanical properties of the soil (cohesion and direct shear). Based on geothecnical mapping, the research area is consist of volcanic breccia and clay. Calculation result using SPT and physical and mechanical properties of the soil in diameter 1,5 able to become the foundation of the area at different depths. The recommended value to use is the SPT test because it gives more bearing capacity value than the physical and mechanical properties of soil test. Which is litologhy suitable for foundation are volcanic breccia.
\end{abstract}

Keywords: Bearing Capacity; bridge; Susukan segment, Standard Penetration Test; Bored Pile Foundation.

*) Korespondensi: rezaafrizona13796@gmail.com 


\section{PENDAHULUAN}

\section{Latar Belakang}

Jembatan Kali Kenteng dan Kali Serang merupakan salah satu proyek dari 4 pembangunan jembatan di ruas jalan tol Salatiga-Kartasura (STA $47+860.50$ 48+348.52). Jembatan yang terletak di terusan Kali Kenteng dan Kali Serang pada daerah Susukan, Salatiga ini merupakan jembatan penghubung jalan tol yang sedang dalam proses pembangunan oleh PT. Waskita Karya. Hal tersebut membuat jalur ini nantinya tidak pernah sepi dilalui oleh kendaraan bermuatan berat ataupun ringan.

Permasalahan yang ditemukan pada sepanjang jalur Salatiga ini adalah akibat morfologi dan kelerengan yang cukup curam, grid elevasinya mencapai $10^{\circ}-15^{\circ}$ yang dapat membahayakan pengguna jalan dan dapat membuat kemacetan panjang (Nailufar, 2018). Penanggulangan masalah tersebut adalah dengan membangun jembatan serta perlu dilakukannya pemeliharaan sarana transportasi ruas jalan tol secara berkala.

Setiap perubahan roman muka bumi untuk keperluan kontruksi suatu bangunan, selalu melibatkan kajian keamanan dan antisipasi agar kontruksi tersebut kuat dan aman. Kondisi kontruksi tersebut diawali dengan pendekatan secara geoteknik. (Zakaria, 2003). Dalam proyek pembangunan jembatan Kali Kenteng dan Kali Serang ini dibutuhkan kajian bidang geoteknik pada lokasi proyek baik pada persebaran tanah dan batuan secara vertical dan lateral. Penyelidikan bawah permukaan mencakup jumlah pengeboran yang cukup untuk mengetahui kondisi dan sifat tanah serta kedalaman batuan dasar. Tanah adalah akumulasi partikel mineral yang tidak mempunyai/lemah ikatan antar partikelnya, yang terbentuk karena pelapukan dari batuan (Craig, 1987).

Penyelidikan geoteknik ini dapat menunjukkan nilai kapasitas daya dukung pondasi untuk menentukan nilai beban yang dapat ditopang pada pondasi (Zufialdi, 2016). Hal tersebut sangat diperlukan untuk menghitung efektivitas dan efisiensi pembuatan pondasi jembatan sebagai rekomendasi desain pondasi tiang pancang jembatan Kali Kenteng dan Kali Serang.

Penelitian ini bertujuan untuk mengetahui kondisi persebaran tanah dan batuan secara vertikal dan lateral disekitar proyek jembatan Kali Kenteng dan Kali Serang, mengetahui sifat fisik dan mekanik untuk menentukan nilai kapasitas daya dukung yang dapat ditopang pada pondasi jembatan Kali Kenteng dan Kali Serang, kemudian mengetahui litologi batuan yang tepat sebagai batuan pondasi jembatan untuk rekomendasi desain pondasi tiang pancang jembatan Kali Kenteng dan Kali Serang.

\section{Lokasi Penelitian}

Jembatan ini merupakan jembatan yang dibangun di atas Kali Kenteng dan Kali Serang. Secara geografis terletak pada koordinat $49 \mathrm{M}$ 434099,564 mE dan 9181160,175 mS (Gambar 1). Secara administratif terletak di Kecamatan Susukan, Kabupaten Semarang, Provinsi Jawa Tengah.

\section{TINJAUAN PUSTAKA}

\section{Geologi Regional}

Stratigrafi regional daerah penelitian yang dimuat dari Peta Geologi Regional daerah Padang menurut Sukardi dan Budhitrisna (1992) daerah penelitian merupakan bagian dari peta geologi Lembar Salatiga, Jawa (Sukardi dan Budhitrisna, 1992) yang dapat dijabarkan sebagai berikut:

Batuan gunungapi menutup tak selaras batuan yang lebih tua dari sedimen Lajur Kendeng, terdiri dari Breksi Gunungapi (Qvb) berumur Plistosen Akhir dan Batuan Gunungapi tak Terpisahkan hasil erupsi G. Ungaran, G. Merbabu dan G. Lawu $(\mathrm{Qv}(\mathrm{u}, \mathrm{m}, \mathrm{l}))$. Secara stratigrafi lokasi penelitian termasuk dalam formasi Batuan Gunungapi Tak Terpisahkan $(\mathrm{Qv}(\mathrm{m}))$ seperti yang ditunjukkan pada Gambar 2. Material penyusun formasi ini berupa breksi gunungapi, lava, tuff, dan breksi lahar. Jika dilihat pada Peta Geologi regional Lembar Salatiga, Jawa (Sukardi dan Budhitrisna, 1992).

\section{Batuan dan Tanah}

Menurut Peck dkk (1996), batuan dianggap sebagai suatu agregat atau butiran mineral yang direkatkan dengan kuat secara permanen, sedangkan menurut Nandi (2010), batuan merupakan kumpulan dari satu atau lebih jenis mineral yang berdasarkan genesa, tekstur dan komposisinya dibagi menjadi 3 yaitu batuan beku, batuan sedimen dan batuan metamorf. Batuan dibutuhkan oleh manusia dalam banyak bidang salah satunya bidang industri-konstruksi. 


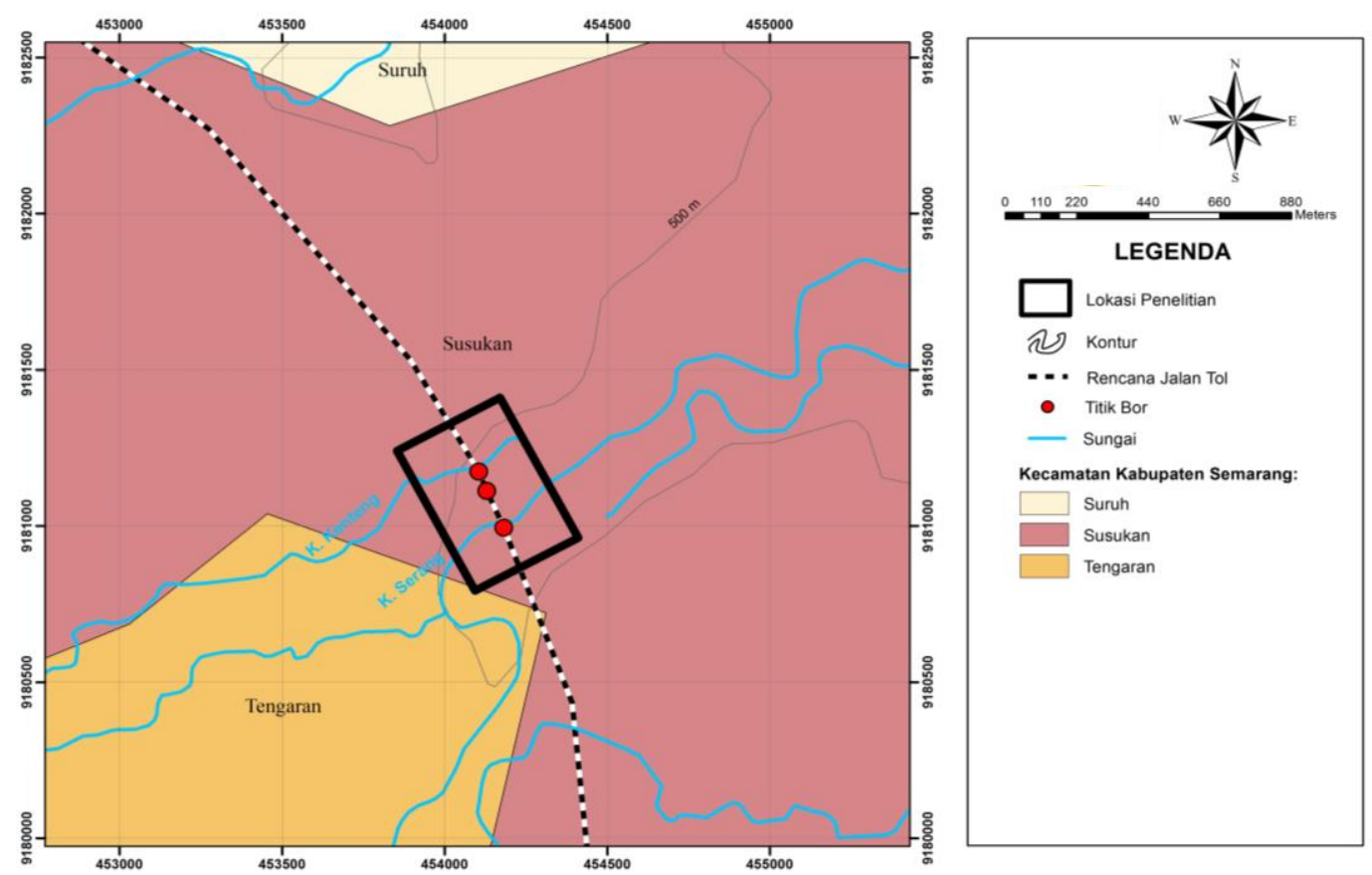

Gambar 1. Peta Lokasi Penelitian (Peta Batas Administrasi Rencana Tata Ruang Kabupaten Semarang 20112031)

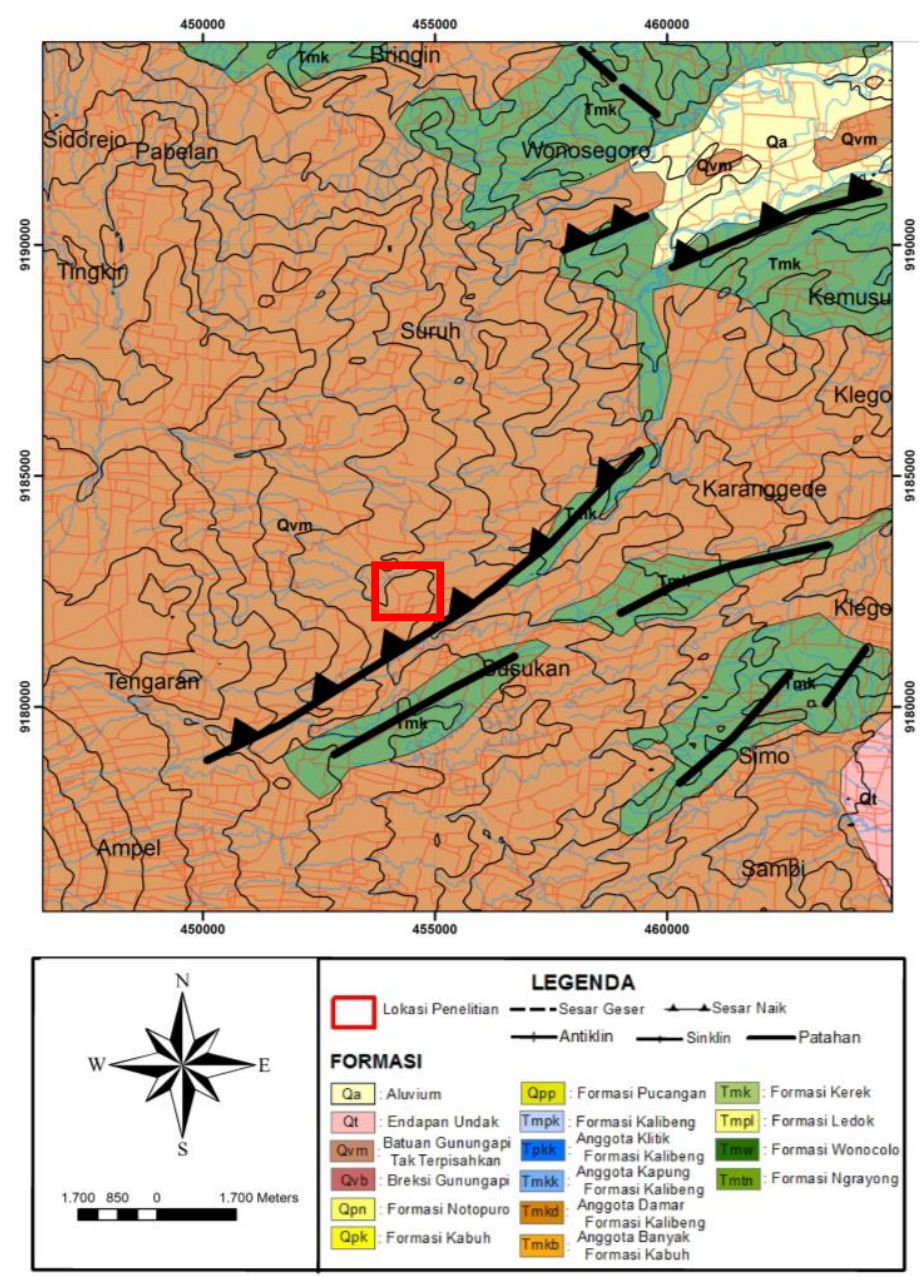

Gambar 2. Peta Geologi Lembar Salatiga, Jawa (Sukardi dan Budhitrisna, 1992). 
Tanah adalah campuran berbagai butiran mineral tanah berbagai ukuran yang terdapat pori-pori diantaranya. Pori-pori ini dapat terisi air ketika dalam keadaan jenuh, terisi air, dan udara ketika dalam keadaan jenuh sebagian dan terisi udara ketika dalam keadaan kering. Butiran ini berasal dari pelapukan batuan secara mekanik dan kimiawi yang dikenal sebagai kerikil, pasir, lanau dan lempung.

Peck dkk. (1996) menyebutkan bahwa tanah dianggap sebagai suatu agregat alam yang berasal dari butiran mineral, dengan atau tanpa adanya material organik, dimana dapat dipisahkan dengan cara mekanis ringan seperti pengadukan dalam air. Tanah dalam teknik sipil dapat didefinisikan sebagai sisa atau produk dari pelapukan secara geologi dimana dapat digali dan diambil sampelnya tanpa perlu dilakukan peledakan dan dapat ditembus dengan peralatan pengeboran (Hendarsin, 2000).

\section{Penyelidikan Geoteknik}

Penyelidikan geoteknik dilakukan untuk mendapatkan data yang dapat digunakan untuk memperoleh gambaran 3D dari lapangan yang akan ditemui dan sangat berpengaruh pada konstruksi dari suatu proyek (Price, 2010). Penyelidikan geoteknik dalam suatu konstruksi ada yang dilakukan di lapangan dan laboratorium. Penyelidikan lapangan mencakup suvei pendahuluan, pengujian penetrasi (Standard Penetration Test dan Cone Penetration Test) dan pengambilan sampel inti tanah (core), sedangkan untuk laboratorium dilakukan uji untuk klasifikasi tanah, uji pemadatan, uji karakteristik kekuatan, uji karakteristik deformasi dan uji permeabilitas air (Sosrodarsono dan Nakazawa, 2000).

\section{Kapasitas Daya Dukung}

Kapasitas Daya Dukung Tiang dari Standard Penetration Test (Meyerhof, 1976)

Tahanan Ujung Tiang $(\mathrm{Qb})$

$\mathrm{fb}=0,4$ N60' (L/d) or $\leq 4$ N60' or $\left(\mathrm{kN} / \mathrm{m}^{2}\right)$

Tahanan Gesek

fs $=1 / 50$ or $\mathrm{N}\left(\mathrm{kN} / \mathrm{m}^{2}\right)$

Tahanan Ujung Tiang $(\mathrm{Qb})$

$f_{b}=19,7 \sigma_{r}\left(N_{60}\right)^{0,36}\left(\mathrm{kN} / \mathrm{m}^{2}\right)$

Tahanan Gesek Satuan

fs $=0,224$ or $\left(\mathrm{N} 60^{\prime}\right) 0,29\left(\mathrm{kN} / \mathrm{m}^{2}\right)$
$\mathrm{Qs}=\Sigma \mathrm{p} \Delta \mathrm{Lf}$

Dengan $\sigma \mathrm{r}=$ tegangan referensi $=100 \mathrm{kN} / \mathrm{m}^{2}$

Kapasitas Daya Dukung Tiang dari Uji Laboratorium

Tekanan Overburden Pada Dasar Pondasi

$\mathrm{P}_{\mathrm{o}}=\mathrm{D}_{\mathrm{f}} \mathrm{x} \gamma$

$\mathrm{P}_{\mathrm{o}}$ : Tekanan overburden

$D_{f}:$ Kedalaman pondasi

$\gamma:$ : Berat volume tanah

Faktor Bentuk Pondasi

Nilai $\mathrm{s}_{\mathrm{c}}$ untuk sembarang $\varphi$ yaitu:

$\mathrm{s}_{\mathrm{c}}=1+0.2(\mathrm{~B} / \mathrm{L}) \operatorname{tg}^{2}(45+\varphi / 2)$

Nilai $\mathrm{s}_{\mathrm{q}}=\mathrm{s}_{\gamma}$ untuk $\varphi \geq 10^{\circ}$ yaitu:

$\left.\mathrm{s}_{\mathrm{q}}=\mathrm{s}_{\gamma}=1+0.1(\mathrm{~B} / \mathrm{L})\right) \operatorname{tg}^{2}(45+\varphi / 2)$

Nilai $\mathrm{s}_{\mathrm{q}}=\mathrm{s}_{\gamma}$ untuk $\varphi=0$ adalah 1

B : Diam pondasi $(\mathrm{m})$

$\mathrm{L}$ : Panjang bentuk dasar pondasi (m)

$\varphi$ : Sudut gesek dalam

$\mathrm{B} / \mathrm{L}=1$ jika pondasi berbentuk lingkaran (tiang)

Faktor Kedalaman Pondasi

Nilai $d_{c}$ untuk sembarang yaitu:

$\mathrm{d}_{\mathrm{c}}=1+0.4(\mathrm{D} / \mathrm{B})$

Nilai $\mathrm{d}_{\mathrm{q}}=\mathrm{d}_{\gamma}$ untuk yaitu:

$\mathrm{d}_{\mathrm{q}}=1+2(\mathrm{D} / \mathrm{B}) \tan \varphi(1-\sin \varphi)^{2}$

Nilai $\mathrm{d}_{\gamma}$ untuk $\varphi=0$ adalah 1

$\mathrm{D}$ : Kedalaman pondasi (m)

B : Diam pondasi (m)

$\varphi$ : Sudut gesek dalam

Jika D/B lebih dari 1 maka D/B diganti

dengan $\operatorname{arc} \tan (\mathrm{D} / \mathrm{B})$

Faktor Kemiringan Beban

Nilai $i_{\mathrm{c}}=\mathrm{i}_{\mathrm{q}}$ untuk sembarang $\varphi$ yaitu:

$\mathrm{i}_{\mathrm{c}}=\mathrm{i}_{\mathrm{q}}=\left[1-\left(\delta^{\circ} / 90^{\circ}\right)\right]^{2}$

Nilai $i_{\gamma}$ untuk $\varphi \geq 10^{\circ}$ yaitu:

$\mathrm{i}_{\gamma}=\left[1-\left(\delta^{\circ} / \varphi\right)\right]^{2}$

Nilai $i_{\gamma}$ untuk $\varphi=0$ adalah 1

$\varphi$ : Sudut gesek dalam

$\delta$ : Sudut kemiringan beban terhadap garis vertikal

Berdasarkan bentuk pondasi, kemiringan beban dan kuat geser tanah di atas dasar pondasinya Meyerhof dan Brinch Hansen memberikan persamaan daya dukung (Hardiyatmo,2006).

$\mathrm{Q}_{\mathrm{u}}=\mathrm{s}_{\mathrm{c}} \mathrm{d}_{\mathrm{c}} \mathrm{i}_{\mathrm{c}} \mathrm{cN} \mathrm{N}_{\mathrm{c}}+\mathrm{s}_{\mathrm{q}} \mathrm{d}_{\mathrm{q}} \mathrm{i}_{\mathrm{q}} \mathrm{P}_{\mathrm{o}} \mathrm{N}_{\mathrm{q}}+\mathrm{s}_{\gamma} \mathrm{d}_{\gamma} \mathrm{i}_{\gamma} 0.5 \mathrm{~B}^{\prime} \gamma \mathrm{N}_{\gamma}$ $\mathrm{Q}_{\mathrm{u}} \quad$ : Kapasitas daya dukung ultimit

$\mathrm{N}_{\mathrm{c}}, \mathrm{N}_{\mathrm{q}}, \mathrm{N}_{\gamma}$ : Faktor kapasitas dukung untuk pondasi memanjang

$\mathrm{s}_{\mathrm{c}}, \mathrm{s}_{\mathrm{q}}, \mathrm{s}_{\gamma} \quad$ : Faktor bentuk pondasi 


$\begin{array}{ll}\mathrm{d}_{\mathrm{c}}, \mathrm{d}_{\mathrm{q}}, \mathrm{d}_{\gamma} & : \text { Faktor kedalaman pondasi } \\ \mathrm{i}_{\mathrm{c}}, \mathrm{i}_{\mathrm{q}}, \mathrm{i}_{\gamma} & : \text { Faktor kemiringan beban } \\ \mathrm{B}{ } & : \text { Lebar pondasi efektif } \\ \mathrm{P}_{\mathrm{o}} & : \text { Tekanan overburden pada dasar } \\ & \text { pondasi } \\ \mathrm{D}_{\mathrm{f}} & : \text { Kedalaman pondasi } \\ \gamma & : \text { Berat volume tanah }\end{array}$

\section{METODOLOGI}

\section{Pemetaan Lapangan}

Penyelidikan tanah dan pemetaan geologi teknik merupakan salah satu tahapan yang sangat penting dalam suatu pekerjaan geologi teknik untuk mengetahui karakteristik tanah di sekitar lokasi dalam hal ini lokasi pengeboran atau lokasi tempat perencanaan dibangunnya jembatan Kali Kenteng dan Kali Serang. Data hasil penyelidikan dan pemetaan geologi teknik dipakai untuk menentukan persebaran lapisan tanah yang kemungkinan akan ditemukan saat melakukan pengeboran, sehingga dapat mempersiapkan peralatan bor yang diperlukan dan juga untuk memperkirakan kendala-kendala yang mungkin terjadi saat pengeboran dilakukan. Di daerah penelitian tidak terdapat singkapan atau lereng yang dapat dianalisis dari segi keteknikan. Penyelidikan dan pemetaan geologi teknik dilakukan dalam area seluas $500 \mathrm{~m}$ x $400 \mathrm{~m}$.

\section{Pengambilan Sampel}

Pengumpulan data primer seperti hasil analisis dilapangan dan laboratorium berupa Grain Size Accumulation Curve (AASHTO Classification) dan sifat fisik mekanik tanah pada masingmasing 3 titik lubang pengeboran yang lokasinya berdekatan dengan titik rencana pondasi jembatan (Gambar 4). Metode pengambilan data bawah permukaan yang dilakukan adalah pengeboran inti (coring) dan untuk Undisturbed Sample (UDS) diambil setiap kedalaman $2 \mathrm{~m}$. UDS kemudian dipersiapkan untuk SPT.

Hasil perhitungan data primer dibandingkan dengan data sekunder sebagai acuan berupa nilai kapasitas daya dukung tanah pondasi jembatan berdasarkan nilai N-SPT. Selanjutnya disusun peta geologi dan geoteknik berdasarkan data lapangan dan uji laboratorium, sehingga diperoleh juga rekomendasi desain pondasi yang efektif untuk menahan beban maksimal pada setiap bored pile. Rekomendasi desain meliputi perbedaan pada kedalaman tertentu dengan kapasitas beban maksimal yang telah diperhitungkan dengan nilai faktor keamanan cukup tinggi.

Penentuan satuan geologi teknik dilakukan berdasarkan hasil dari analisis laboratorium, antara lain deskripsi, sifat fisik dan sifat mekanik dari tanah. Sifat keteknikan tersebut berdasarkan sampel yang diambil dari hasil pengeboran.

\section{Uji Laboratorium}

\section{Analisis distribusi ukuran butiran}

Distribusi ukuran butiran (Grain Size Analysis) adalah penentuan persentase berat butiran pada satu unit saringan, dengan ukuran diam lubang tertentu. Bertujuan untuk pengelompokkan tanah seperti: tanah berbutir kasar tersusun dari material berukuran kerikil dan pasir, tanah berbutir halus tersusun dari material berukuran lanau dan lempung.

Pengukuran butiran dilakukan analisis/ tes ayakan berdasarkan masing-masing kedalaman tiap $5 \mathrm{~m}$ serta ukuran Butir dikatakan seragam apabila: Tidak Seragam: $5<\mathrm{Cu}<15$, Seragam: $\mathrm{Cu} \leq 5$, gradasi sangat baik apabila $\mathrm{Cu}>15$, baik mempunyai nilai $1<\mathrm{Cc}<3$ apabila $\mathrm{Cu}>4$ (untuk tanah kerikil) dan $\mathrm{Cu}>6 / \mathrm{Cc}<6$ (untuk pasir), serta Cc antara $1-3$ (untuk kerikil dan pasir).

Analisis kadar air, berat isi, berat jenis, dan uji geser langsung

Analisis kadar air, berat isi, berat jenis dan uji geser langsung menggunakan contoh sampel tak terganggu (UDS) dari 3 sumur pada setiap kedalaman 4-6 m.

\section{Daya Dukung Tanah Pondasi Tiang Pancang Berdasarkan Nilai N-SPT}

Penentuan kapasitas daya dukung tanah pondasi tiang pancang menggunakan data hasil uji Standard Penetration Test (SPT) dapat dilakukan dengan melakukan perhitungan terhadap param N-SPT yang didapatkan selama pengujian dilaksanakan. Pengujian SPT dalam penelitian ini dilakukan setiap $2 \mathrm{~m}$ kedalaman pada saat dilakukan pengeboran inti (coring), sehingga akan ditemukan 2-3 sampel SPT pada setiap core box.

Perhitungan nilai kapasitas daya dukung tanah menggunakan 1 jenis diam tiang pancang. Hal ini bertujuan untuk memperkirakan diam yang lebih efektif dan efisien untuk 
dipergunakan dalam proyek ini. Diam tiang pancang yang dipakai dalam penelitian ini adalah $1.5 \mathrm{~m}$.

Faktor keamanan yang dipakai dalam perhitungan ini sebesar 3. Penggunaan nilai faktor keamanan ini karena nilai tersebut adalah nilai keamanan tertinggi (Hardiyatmo, 2006). Nilai faktor keamanan tertinggi menunjukkan nilai beban maksimum yang dihasilkan akan lebih kecil dibandingkan jika menggunakan faktor keamanan kecil. Hal ini bertujuan agar beban yang akan melewati jembatan tidak akan melampaui beban maksimum, sehingga begitu umur (life span) dari jembatan akan lebih panjang.

\section{HASIL}

\section{Kapasitas Beban Maksimal Berdasarkan Nilai SPT}

Perhitungan kapasitas beban maksimal pada setiap titik pengeboran berdasarkan nilai N-SPT dengan diam tiang 1,5 m. Perhitungan kapasitas beban maksimal yang didapatkan berupa nilai daya dukung ultimit (Qult) dan daya dukung yang diijinkan (Qa). Rekapitulasi perhitungan data BH-1 dapat dilihat pada Tabel 1 dan grafik perubahan kapasitas daya dukung terhadap kedalaman ditampilkan pada Gambar 3. Perhitungan daya dukung tanah pondasi mengggunakan persamaan Meyerhoff (Hardiyatmo, 2010). Contoh perhitungan yang dilakukan pada ketiga titik penelitian:

\section{Bore Hole 1}

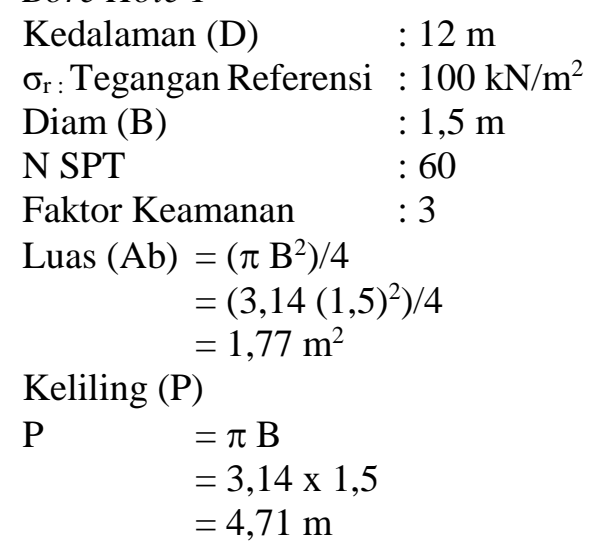

\section{Tahanan Ujung Satuan Tiang}

Tahanan ujung satuan tiang (fb) dilakukan karena berada di area dengan dominasi lempung. Perhitungan tahanan ujung satuan tiang $(\mathrm{Qb})$ dan perhitungan tekanan gesek selimut tiang (Qs) menggunakan persamaan Meyerhoff (1976).

$$
\begin{array}{rl}
\mathrm{fb} & =0,4 \mathrm{~N} "(\mathrm{D} / \mathrm{B}) \sigma_{\mathrm{r}} \leq 3 \mathrm{~N} " \sigma_{\mathrm{r}} \\
& =0,4 \times 60(12 / 1,5) 100<3 \times 60 \times 100 \\
& =19.200 \mathrm{kN} / \mathrm{m}^{2} \\
\mathrm{Qb} & =\mathrm{Ab} . \mathrm{Fb} \\
& =1,76 \times 19200 \\
& =33.792 \mathrm{kN} / \mathrm{m}^{2} \\
\mathrm{Qs} & \mathrm{P} . \mathrm{fs} \\
& =4,71 \times 1 / 50 \sigma_{\mathrm{r}} \mathrm{N} \\
& =565,2 \mathrm{kN} / \mathrm{m}^{2}
\end{array}
$$

\section{Kapasitas Daya Dukung Maksimum}

Kapasitas daya dukung ultimit $\left(\mathrm{Q}_{\text {ult }}\right)$ dihitung serta kapasitas daya dukung yang diijinkan $\left(\mathrm{Q}_{\mathrm{a}}\right)$ dihitung menggunakan persamaan sebagai berikut.

$$
\begin{aligned}
\text { Qult } & =\mathrm{Qb}+\mathrm{Qs} \\
& =33.792+565,2 \\
& =34357,2\left(\mathrm{kN} / \mathrm{m}^{2}\right)=3503,46 \text { ton } \\
\mathrm{Qa} & =\mathrm{Qu} / \mathrm{Fs} \\
& =3.503,46 / 3 \\
& =1.167,82 \text { ton }
\end{aligned}
$$

Perhitungan diatas menunjukkan bahwa daya dukung ultimit atau beban maksimal adalah sebesar 3.503,46 ton dan daya dukung atau beban yang diijinkan adalah sebesar 1167,82 ton. Daya dukung yang diijinkan merupakan hasil beban maksimal dibagi dengan faktor keamanan yang disepakati yaitu 3. Hal ini bertujuan untuk mencegah masuknya pondasi kedalam tanah karena beban yang terlalu berat maka beban maksimal yang dapat ditahan oleh tanah harus dibagi 3 (faktor keamanan terbesar) pada setiap tiang jika tiang yang dipakai berdiam 1.5 m pada kedalaman $12 \mathrm{~m}$.

Hasil perhitungan lengkap untuk 3 titik Bore Hole dan pada 1 jenis diam yakni $1.5 \mathrm{~m}$. Dilakukan dengan menggunakan software Microsoft Excel. Hasil perhitungan tersebut mencakup sesuai dengan kedalaman setiap bor, karena hanya difokuskan pada lapisan yang cukup mempengaruhi rencana dasar pondasi yaitu pada lapisan yang kekuatannya kurang

\section{Daya Dukung Tanah Pondasi Bored Pile}

Penentuan kapasitas daya dukung tanah pondasi bored pile menggunakan data sifat fisik dan mekanik tanah dapat dilakukan dengan melakukan perhitungan terhadap nilai kohesi (c), sudut geser dalam $(Q)$, berat jenis (Gs) dan berat isi $(\gamma)$ yang didapatkan selama pelaksanaan uji laboratorium. Uji laboratorium ini dilakukan terhadap sampel tanah tak terganggu (UDS) yang diambil setiap $5 \mathrm{~m}$ kedalaman pada saat 
dilakukan pengeboran inti (coring), sehingga akan ditemukan 1 sampel UDS pada setiap core box.

Perhitungan nilai kapasitas daya dukung tanah berdasarkan parameter fisik dan mekanik tanah tetap menggunakan jenis diam tiang bored pile yaitu $1,5 \mathrm{~m}$. Faktor keamanan yang digunakan dalam perhitungan daya dukung adalah 3.

Perhitungan kapasitas beban maksimal pada setiap titik pengeboran berdasarkan nilai param fisik dan mekanik tanah dengan diam tiang 1,5 m dapat dilakukan pada aplikasi Microsoft Excel dengan memasukkan rumus-rumus dasar dan data yang diperoleh. Dengan begitu dapat diperkirakan nilai kapasitas beban maksimal bored pile.

Perhitungan kapasitas beban maksimal yang didapatkan berupa nilai daya dukung ultimit (Qu) dan daya dukung yang diijinkan (Qa). Perhitungan daya dukung tanah pondasi mengggunakan persamaan Meyerhoff (1963) dan Hansen (1961) dalam Hardiyatmo (2006). Berikut contoh perhitungan untuk menentukan kapasitas beban maksimal tanah pondasi bored pile berdasarkan nilai param fisik dan mekanik tanah pada borehole 1 kedalaman $10 \mathrm{~m}$ menggunakan diam tiang $1,5 \mathrm{~m}$.

Bore Hole 1

$\begin{array}{ll}\text { Kedalaman (D) } & : 12 \mathrm{~m} \\ \text { Diam }(\mathrm{B}) & : 1,5 \mathrm{~m} \\ \text { Faktor aman }(\mathrm{Fs}) & : 3 \\ \gamma \text { Sat } & : 14,54 \mathrm{kN} / \mathrm{m}^{2} \\ \phi & : 30^{0} \\ \mathrm{C} & : 8,44 \mathrm{kN} / \mathrm{m}^{2} \\ \text { Luas }\left(\mathrm{A}_{\mathrm{b}}\right) & =\left(\pi \mathrm{B}^{2}\right) / 4 \\ & =\left(3,14(1,5)^{2} / 4\right. \\ & =1,77 \mathrm{~m}^{2} \\ \text { Keliling }(\mathrm{P}) & =\pi \mathrm{B} \\ & =3,14 \times 1,5 \\ \mathrm{C} & =4,71 \mathrm{~m} \\ \mathrm{~N}_{c} \cdot 7,5 ; \quad \mathrm{N} \cdot 8 \mathrm{dan} & \mathrm{N} \cdot 4.75\end{array}$

$\mathrm{N}_{\mathrm{c}}: 7,5 ; \mathrm{N}_{\mathrm{q}}: 8$ dan $\quad \mathrm{N}_{\gamma}: 4,75$

\section{Tekanan overburden (Po)}

$$
\begin{aligned}
\text { Po } & =10 \times \gamma \\
& =10 \times 14,54 \\
& =145,4 \mathrm{kN} / \mathrm{m}^{3}
\end{aligned}
$$

\section{Faktor bentuk pondasi}

$$
\begin{aligned}
\mathrm{S}_{\mathrm{c}} & =1+0,2(\mathrm{~B} / \mathrm{L}) \operatorname{tg}^{2}(45+\varphi / 2) \\
& =1+0,2(1) \operatorname{tg}^{2}(45+30 / 2) \\
& =1,6 \mathrm{kN} / \mathrm{m}^{2}
\end{aligned}
$$

$$
\begin{aligned}
\mathrm{s}_{\mathrm{q}}=\mathrm{s}_{\gamma} & =1+0,1(\mathrm{~B} / \mathrm{L})) \operatorname{tg}^{2}(45+\varphi / 2) \\
& =1+0,1(1) \operatorname{tg}^{2}(45+30 / 2) \\
& =1,3 \mathrm{kN} / \mathrm{m}^{2}
\end{aligned}
$$

Faktor kedalaman pondasi

$$
\begin{aligned}
\mathrm{d}_{\mathrm{c}}= & 1+0,4(\mathrm{D} / \mathrm{B}) \\
& =1+0,4 \operatorname{arc} \tan (\mathrm{D} / \mathrm{B}) \\
& =1+0,4 \arctan (12 / 1,5) \\
& =34,15 \mathrm{kN} / \mathrm{m}^{2} \\
\mathrm{~d}_{\mathrm{q}} & =1+2(\mathrm{D} / \mathrm{B}) \tan \varphi(1-\sin \varphi)^{2} \\
& =1+2(12 / 1,5) \tan 30(1-\sin 30)^{2} \\
& =3,31 \mathrm{kN} / \mathrm{m}^{2} \\
\mathrm{~d}_{\gamma} & \text { adalah } 1
\end{aligned}
$$

\section{Faktor kemiringan beban}

$\mathrm{i}_{\mathrm{c}} ; \mathrm{i}_{\mathrm{q}} ; \mathrm{i}_{\gamma}=1$

\section{Kapasitas daya dukung maksimum}

$$
\begin{aligned}
\mathrm{Q}_{\mathrm{u}}= & \mathrm{s}_{\mathrm{c}} \mathrm{d}_{\mathrm{c}} \mathrm{i}_{\mathrm{c}} \mathrm{cN}_{\mathrm{c}}+\mathrm{s}_{\mathrm{q}} \mathrm{d}_{\mathrm{q}} \mathrm{i}_{\mathrm{q}} \mathrm{P}_{\mathrm{o}} \mathrm{N}_{\mathrm{q}}+\mathrm{s}_{\gamma} \mathrm{d}_{\gamma} \mathrm{i}_{\gamma} 0,5 \\
\mathrm{~B}^{\prime} \gamma \mathrm{N}_{\gamma} & \\
= & (1,6 \times 34,15 \times 1 \times 15 \times 32)+(1,3 \times 3,31 \times 1 \\
& \mathrm{x} 145,4 \times 19)+(1,3 \times 1 \times 1 \times 0,5 \times 1,5 \times 1 \\
& 19,4 \times 17) \\
= & 35.485,13 \mathrm{kN} / \mathrm{m}^{2} \\
= & 3.618,47 \mathrm{ton} / \mathrm{m}^{2} \\
\mathrm{Q}_{\mathrm{a}}= & \mathrm{Q}_{\mathrm{u}} / \mathrm{Fs} \\
= & 3618,47 / 3 \\
= & 1.206,16 \text { ton }
\end{aligned}
$$

Tabel 1. Perhitungan Daya Dukung Tiang Diam 1.5 m pada BH-1 Berdasarkan Nilai N-SPT dan Nilai Fisik-Mekanik

\begin{tabular}{ccc}
\hline $\begin{array}{c}\text { Kedalaman } \\
(\mathrm{m})\end{array}$ & $\begin{array}{c}\text { Qall } \\
(\mathrm{N}-\mathrm{SPT})\end{array}$ & $\begin{array}{c}\text { Qall (Sifat } \\
\text { Fisik\&Mekanik) }\end{array}$ \\
\hline 1 & 1.066 & 37 \\
2 & 1.955 & 509 \\
3 & 2.061 & 616 \\
4 & 2.132 & 690 \\
5 & 2.132 & 748 \\
6 & 2.132 & 801 \\
7 & 2.132 & 1.047 \\
8 & 2.132 & 1.109 \\
9 & 2.132 & 1.173 \\
10 & 2.132 & 1.239 \\
11 & 2.132 & 1.309 \\
12 & 2.132 & 1.381 \\
\hline
\end{tabular}




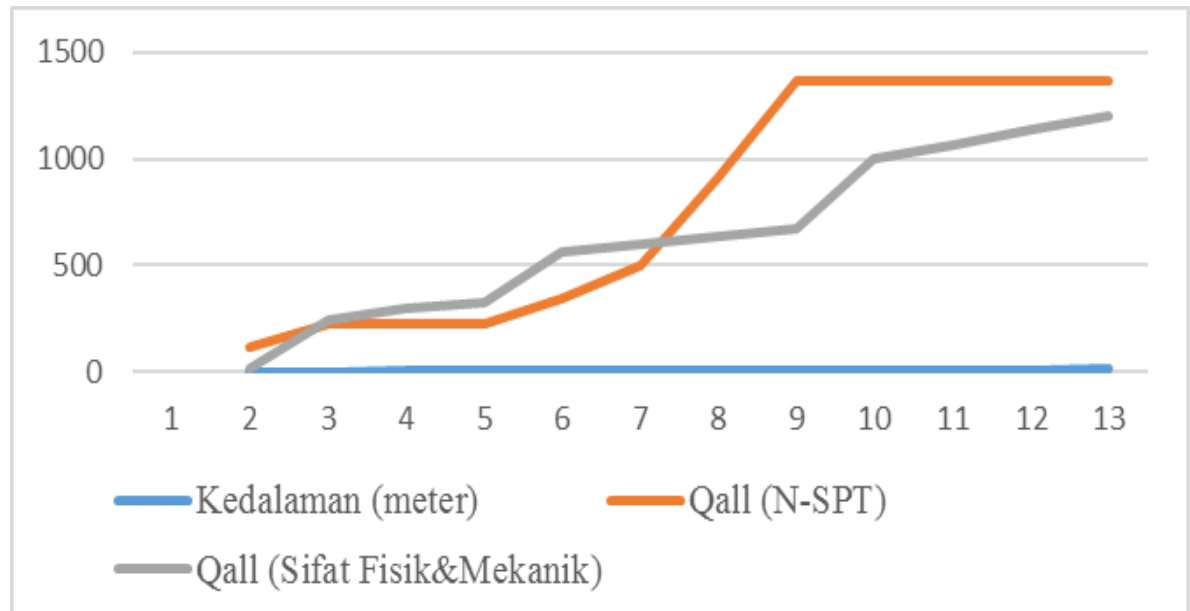

Gambar 3. Grafik Kapasitas Daya Dukung dan Beban menggunakan Uji SPT BH-1.

Perhitungan diatas menunjukkan bahwa daya dukung ultimit atau beban maksimal adalah sebesar 4.688 ton dan daya dukung atau beban yang diijinkan adalah sebesar 1.563 ton. Daya dukung yang diijinkan merupakan hasil beban maksimal dibagi dengan faktor keamanan yang disepakati yaitu 3. Hal ini bertujuan untuk mencegah masuknya pondasi kedalam tanah karena beban yang terlalu berat maka beban maksimal yang dapat ditahan oleh tanah harus dibagi 3 (faktor keamanan terbesar) pada setiap tiang jika tiang yang dipakai berdiam $1,5 \mathrm{~m}$ pada kedalaman $12 \mathrm{~m}$.

Hasil perhitungan lengkap untuk kelima titik bore hole dan pada jenis diam tiang 1,5 dilakukan dengan menggunakan software Microsoft Excel. Hasil perhitungan dilakukan pada kedalaman masing masing bor yang dinilai cukup berpengaruh pada rencana dasar pondasi.

\section{PEMBAHASAN}

\section{Geologi dan Geologi Teknik Lokasi Penelitian}

Lokasi penelitian banyak dimanfaatkan untuk pemukiman dan lahan pertanian karena memiliki topografi landai. Titik pengeboran berada di tepian Kali Kenteng dan Kali Serang yang kemudian akan dilaksanakan pembangunan jembatan baru. Kali Kenteng dan Kali Serang ini memiliki tepian yang terjal dengan panjang jembatan sekitar $40 \mathrm{~m}$ dan tinggi sekitar $30 \mathrm{~m}$. Kali Kenteng dan Kali Serang juga memiliki debit air yang cukup besar dan merupakan sungai dewasa.

Setelah dilakukan pemetaan geologi daerah penelitian, litologi yang tersingkap di permukaan adalah breksi vulkanik dan alluvium. Hal ini membuat proses penentuan satuan wilayah dibagi atas dasar perkiraan batuan dasar menurut persebaran jenis tanah yang ditemukan. Satuan tanah yang ditemukan yakni satuan breksi vulkanik dan satuan alluvium dengan ukuran halus hingga kasar berwarna coklat kekuningan, dan terdapat fragmen kerikil hingga bongkah. Peta Geologi hasil pemetaan sekitar Kali Kenteng dan Kali Serang dapat dilihat pada Gambar 5. Satuan batuan dan tanah dilokasi penelitian terbagi menjadi dua satuan utama yaitu satuan breksi vulkanik dan satuan lempung.

\section{Satuan Breksi Vulkanik}

Batuan tersebut memiliki ciri-ciri berwarna kuning kecoklatan dengan ukuran butir sedimen berbutir kerikil-brangkal. Material penyusun dari batuan tersebut kemungkinan berasal dari proses vulkanisme erupsi gunungapi. Hal ini disebabkan karena material penyusun satuan batuan ini terdapat material piroklastik berupa tuff berukuran pasir halus. Kondisi lapuk sedang dan lapuk ringan

Berdasarkan analisis satuan batuan ini, batuan ini diidentifikasi sebagai breksi vulkanik, satuan ini sangat dikontrol oleh proses erupsi atau vulkanisme gunung api. Menurut (Sukardi dan Budhitrisna, 1992), satuan ini termasuk kedalam Formasi Batuan Gunungapi tak Terpisahkan yang berumur Plistosen Akhir.

\section{Satuan Lempung}

Satuan ini merupakan satuan tanah dengan ciriciri berwarna coklat dan didominasi oleh material dengan ukuran butiran lempung dan juga pada beberapa lokasi terdapat material berukuran pasir, kerikil dalam jumlah sedikit. 
Satuan tanah ini kemungkinan merupakan satuan tanah yang berasal dari lapukan tanah di bawahnya atau di daerah sekitarnya. Persebaran satuan tanah ini banyak terdapat di sekitaran Kali Kenteng dan Kali Serang. Satuan ini memiliki persebaran paling luas di daerah penelitian.

Secara umum satuan ini dapat disebut sebagai satuan tanah lempung berdasarkan penamaan USCS (Unified Soil Classification System), sedangkan berdasarkan analisis tanah tersebut dan keberadaannya yang cenderung merupakan hasil transportasi, satuan ini diidentifikasi sebagai lempung (Wesley, 2012).

\section{Kapasitas Daya Dukung dan Beban yang Diijinkan}

Pada perhitungan tabel diatas menunjukkan nilai daya dukung ijin (Qa) yang dihitung dengan metode SPT dari 1 jenis tiang pada kedalaman tiap bor. Metode memiliki kelebihan dan kelemahan dalam memprediksi kapasitas daya dukung tanah pondasi.

Metode SPT dilakukan untuk menentukan kepadatan dan konsistensi relatif tanah secara dinamis, sehingga proses pengambilan data dilakukan secara praktis yaitu dengan melakukan penetrasi tabung kedalam tanah dengan beban tertentu. Objek yang menjadi sudut pandang adalah kepadatan tanah dinilai dari jumlah pukulan yang diberikan pada setiap kedalaman penetrasi tabung kedalam tanah. Kelebihan yang didapat adalah proses akuisisi lebih cepat dan merepresentasikan sifat asli dari tanah di lapangan. Kekurangannya adalah contoh sampel kurang dapat diidentifikasi dengan jelas.

\section{Rekomendasi Pondasi Jembatan}

Berdasarkan hasil analisis daya dukung diatas, dapat disimpulkan daya dukung yang lebih direkomendasikan yakni memakai Uji SPT dengan diam 1,5 karena memiliki nilai daya dukung yang lebih besar dibandingkan dengan metode sifat fisik dan mekanik tanah hal ini dikarenakan nilai N-SPT akan cenderung semakin besar dan memungkinkan mencapai nilai maksimum lebih cepat. Selain itu sampel UDS dengan SPT maksimum kurang mewakili kondisi lapisan di bawah permukaan. Maka dari itu PT. Waskita Karya menggunakan diam 1,5 yang sudah sesuai dengan standar pembebanan jembatan, yakni dengan menggunakan rumus yang ditetapkan oleh Converse-Labbare, yaitu nilai Daya dukung tiang bor berkelompok lebih besar nilainya dari beban tiang.

Perhitungan di BH-1 pada kedalaman $1 \mathrm{~m}$

Rumus beban tiang

$$
\begin{aligned}
\mathrm{N} & =\mathrm{P} / \mathrm{Qu} \\
\mathrm{P} & =\mathrm{N} \cdot \mathrm{Qa} \\
& =5.114 \\
& =570 \text { ton }
\end{aligned}
$$

Pada Proyek jembatan tersebut sudah dirancang yakni bored pile kelompok yang dimana jumlah bored pile pada kelompok tersebut ada 5 buah, maka

$$
\mathrm{E}_{\mathrm{g}}=1-\theta \frac{(n-1) m+(m-1) n}{90 m n}
$$

Keterangan :

$\mathrm{Eg}=$ Efisiensi kelompok tiang

$\theta=\operatorname{arctg}(\mathrm{d} / \mathrm{s}$ dalam derajat $)$

$\mathrm{m}=$ Jumlah baris tiang

$\mathrm{n}=$ Jumlah tiang dalam satu baris

Maka

$\mathrm{Eg}=1-9,48^{\circ} \times \frac{(5-1) 2+(2-1) 5}{90.2 .5}$

$$
=0,863
$$

$\mathrm{Eg}=1-8,53^{\circ} \times \frac{(5-1) 2+(2-1) 5}{90.2 .5}$

$$
=0,876
$$

Verifikasi dilakukan dengan menggunakan rumus beban maksimum kelompok tiang.

Qg = Eg $\mathrm{x}$ jumlah bored pile $\mathrm{x}$ daya dukung tiang $(\mathrm{Qu})$

$$
=0,863 \times 5 \times 342
$$

$$
=1.475,73 \text { ton }
$$

Qg = Eg $\mathrm{x}$ jumlah bored pile $\mathrm{x}$ daya dukung tiang $(\mathrm{Qu})$

$$
\begin{aligned}
& =0,876 \times 5 \times 342 \\
& =1.497,96 \text { ton }
\end{aligned}
$$

Maka $1475,73>570($ Jarak $9 \mathrm{~m})$ $1497,96>570($ Jarak $10 \mathrm{~m})$

\section{Rancangan Pondasi Jembatan}

Rencana pembuatan pondasi pada jembatan Kali Kenteng dan Kali Serang bertujuan agar beban jembatan dan kendaraan maksimal dapat disalurkan menuju tanah keras pada kedalaman tertentu di bawah permukaan tanah. Pada proyek jembatan ini menggunakan pondasi bored pile sebagai penahan jembatan. Penentuan lapisan 


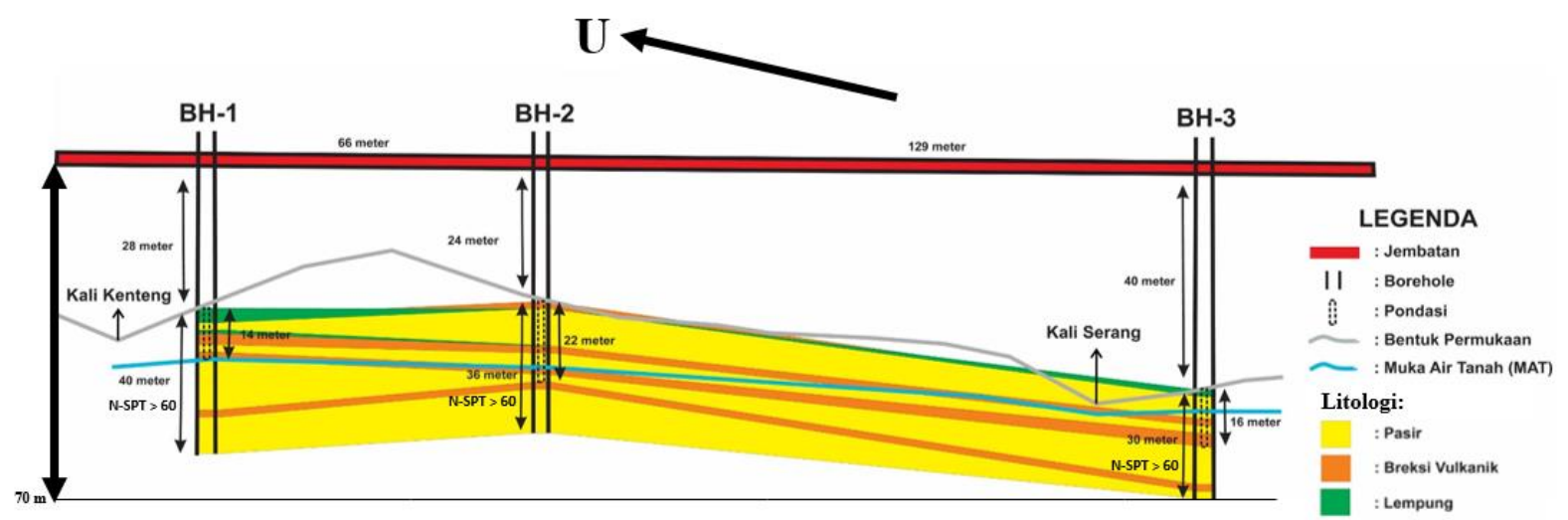

Gambar 7. Denah Rancangan Pondasi Bored Pile Tanpa Skala

Tabel 2. Nilai daya dukung yang diijinkan dan kedalaman pada tiap tiang pondasi.

\begin{tabular}{ccccc}
\hline $\begin{array}{c}\text { Titik } \\
\text { Bor }\end{array}$ & $\begin{array}{c}\text { Diameter } \\
\text { Tiang } \\
(\mathrm{m})\end{array}$ & $\begin{array}{c}\text { N- } \\
\text { SPT }\end{array}$ & $\begin{array}{c}\text { Daya } \\
\text { Dukung } \\
\text { Diijinkan } \\
\text { (Ton) }\end{array}$ & $\begin{array}{c}\text { Kedalaman } \\
\text { Tiang } \\
\text { Pondasi (m) }\end{array}$ \\
\hline BH-1 & 1,5 & $>60$ & 1.364 & 14 \\
BH-2 & 1,5 & $>60$ & 2.132 & 22 \\
BH-3 & 1,5 & $>60$ & 1.556 & 16 \\
\hline
\end{tabular}

tanah yang keras, dilakukan pengeboran inti dan Uji SPT, berdasarkan hasil dari pengeboran inti dan Uji SPT, dapat diketahui lapisan tanah yang keras, yang dapat digunakan sebagai dasar pondasi.

Berdasarkan hasil dari pengeboran, pondasi yang dibuat berada sama atau lebih dalam daripada muka air tanah (MAT), pada borehole 1 muka air tanah (MAT) berada pada kedalaman $14 \mathrm{~m}$ atau sama dengan kedalaman pondasi. Kemudian pada borehole 2 muka air tanah (MAT) berada pada kedalaman $20 \mathrm{~m}$ atau lebih dangkal daripada pondasi, serta muka air tanah (MAT) pada borehole 3 memiliki kedalaman yang lebih dangkal daripada pondasi yaitu $6 \mathrm{~m}$.

Litologi yang diperoleh berdasarkan hasil pengeboran dibagi menjadi 3 yaitu pasir, breksi vulkanik, dan lempung. Berdasarkan geologi regional material penyusun pasir dan breksi vulkanik berasal dari endapan G. Ungaran, G. Merbabu, G. Lawu yang berumur Plistosen Akhir. Pada material penyusun lempung berasal dari lapukan material sebelumnya yang berumur Kuarter.

Hasil dari sifat fisik dan mekanik dari tiap litologi memiliki nilai yang berbeda, berdasarkan hasil laboratorium litologi yang memiliki kadar air paling besar yaitu sebesar $48 \%$ adalah lempung, serta memiliki sudut geser dalam yang paling rendah yaitu $20^{\circ}$. Pada litologi pasir memiliki kadar air sebesar 38\% dan sudut geser dalam sebesar $24^{\circ}$. Serta litologi yang memiliki kadar air paling rendah adalah breksi vulkanik yaitu sebesar $33 \%$ dengan sudut geser dalam paling tinggi yaitu $30^{\circ}$.

Lapisan tanah keras direkomendasikan sebagai dasar pondasi sebagai penahan beban jembatan. Lapisan tanah keras tersebut yakni mempunyai jenis litologi breksi vulkanik, dimana breksi vulkanik tersebut mempunyai nilai SPT lebih dari 60. Setiap borehole mempunyai total kedalaman yang bervariasi, maka dari itu lapisan breksi vulkanik tersebut terdapat dikedalaman yang berbeda-beda pada setiap borehole.

Terdapat perbedaan pada tiap kedalaman pondasi tiang pancang yang direkomendasikan berdasarkan perhitungan menggunakan metode SPT dan sifat fisik mekanik tanah (Tabel 2). Berdasarkan hasil rancangan diatas maka dapat diketahui kapasitas daya dukung yang diijinkan pada setiap tiang di titik pengeboran sehingga kedalaman berbeda beda dari setiap borehole.

Pada Tabel 2 terlihat tiang untuk BH-2 memiliki kedalaman yang terdalam yaitu $22 \mathrm{~m}$, karena pada kedalaman tersebut kondisi tiang pada $\mathrm{BH}-$ 2 menembus lapisan breksi vulkanik yang berada dibawahnya karena lapisannya tidak terlalu jauh apabila dibandingkan $\mathrm{BH}-1$ dan $\mathrm{BH}-$ 3. Dari hasil daya dukung yang diijinkan dan kedalaman pondasi tiang di tiap titik pengeboran maka area tiang pancang yang digunakan pada bagian jembatan Kali Kenteng dan Kali Serang.

\section{KESIMPULAN}

Daerah penelitian tersusun dari dua satuan yaitu satuan breksi vulkanik dan satuan lempung. Susunan lapisan tanah dari atas ke bawah terdiri 
dari lempung pasiran berwarna coklat bersifat teguh memiliki nilai N-SPT 4 sampai 14, pasir lanauan berwarna coklat bersifat keras memiliki nilai N-SPT 18 sampai 50, dan gravel pasiran berwarna abu-abu bersifat kaku-sangat kaku memiliki nilai N-SPT $>60$.

Rekomendasi kapasitas daya dukung berdasarkan Uji SPT: 1) pada sekitar titik pemboran $\mathrm{BH}-1$ menggunakan tiang pancang diam $=1,5 \mathrm{~m}$ sampai kedalaman $14 \mathrm{~m}$ dengan nilai N-SPT 60 daya dukung yang diijinkan tiap satu tiang sebesar 1364,01 ton; 2) pada sekitar titik pemboran $\mathrm{BH}-2$ menggunakan tiang pancang diam $=1,5 \mathrm{~m}$ sampai kedalaman $22 \mathrm{~m}$ dengan nilai N-SPT 60, daya dukung yang diijinkan tiap satu tiang sebesar 2132,47 ton; dan 3) pada sekitar titik pemboran BH-3 menggunakan tiang pancang diam $=1,5 \mathrm{~m}$ sampai kedalaman 16 m dengan nilai N-SPT 60, daya dukung yang diijinkan tiap satu tiang sebesar 1556,13 ton.

\section{UCAPAN TERIMAKASIH}

Terima kasih kepada PT. Waskita Karya (Persero) Tbk. Jawa Tengah atas ketersediaannya memberikan data dan ijin penelitian yang dilakukan pada area Pembangunan Jembatan Tol Salatiga-Kartasura.

\section{DAFTAR PUSTAKA}

Hardiyatmo, H. C. 2006. Teknik Pondasi 2. Beta Offset: Yogyakarta.

Hardiyatmo, H. C. 2010. Analisa dan Perancangan Fondasi II. Gadjah Mada University Press: Yogyakarta.

Hendarsin, S. L. 2000. Perencanaan Teknik Jalan Raya. Politeknik Negeri Bandung: Bandung.

Nailufar, N., 2018. Jalur Bawah Jembatan Kali Kenteng Semarang Curam, Polisi Alihkan Pemudik via Arteri: KOMPAS.

Nandi, 2010. Batuan, Mineral dan Batubara, Jurusan Pendidikan Geografi. Universitas Pendidikan Indonesia: Bandung.

Peck, R. B., Hanson, Walter E., dan Thornburn, Thomas H., 1996. Teknik Fondasi. Gadjah Mada University: Yogyakarta.

Price, D. G., 2010. Engineering Geology Principles and Practice. Imperial College London: London, UK.
Sosrodarsono, S., Nakazawa, K. 2000. Mekanika Tanah dan Teknik Pondasi. Pradnya Paramita: Jakarta.

Sukardi dan Budhitrisna, T. 1992. Peta Geologi Regional Lembar Salatiga, skala 1 : 100.000. Pusat Penelitian dan Pengembangan Sumber Daya Geologi: Jakarta.

Wesley, L. D., 2012. Mekanika Tanah, untuk Endapan dan Residu Edisi 1. ANDI: Yogyakarta.

Zufialdi, Z., Jihadi, L.H. 2016. Peran Ilmu Dasar dalam Geoteknik untuk Menunjang Pembangunan Berkelanjutan yang Berwawasan Lingkungan, Bulletin of Scientific Contribution, Volume 14, Nomor 3, Desember 2016 : 239 - 250 . 